\title{
Revising, reforming, reframing: Report of the Expert Group on the Review of the Mental Health Act 2001 (2015)
}

\author{
B. D. Kelly * \\ Department of Adult Psychiatry, UCD School of Medicine and Medical Science, Mater Misericordiae University Hospital, University College Dublin, Dublin, Ireland
}

\begin{abstract}
Involuntary psychiatric admission and treatment in Ireland is chiefly governed by the Mental Health Act 2001. The Irish government announced a review of the 2001 Act in July 2011, and the Report of the Expert Group on the Review of the Mental Health Act 2001 was published on 5 March 2015. The report, which constitutes advice to the Minister for Primary Care, Social Care (Disabilities \& Older People) and Mental Health, presents 165 recommendations relating to virtually all areas of the Act. It recommends that 'insofar as practicable, a rights based approach should be adopted throughout any revised mental health legislation' and that the principle of 'best interests' should be replaced by an alternative set of principles as follows: 'the enjoyment of the highest attainable standard of mental health, with the person's own understanding of his or her mental health being given due respect; autonomy and self-determination; dignity (there should be a presumption that the patient is the person best placed to determine what promotes/compromises his or her own dignity); bodily integrity; and least restrictive care'. The Report presents a series of other recommendations aimed at increasing multi-disciplinary involvement in key decisions, promoting human rights and strengthening inspections of community facilities. Overall, the package of measures outlined in the Report is complex, interesting and worthy of debate.
\end{abstract}

Received 12 March 2015; Revised 12 March 2015; Accepted 13 March 2015

Key words: Dignity, human rights, legislation, mental disorders, psychiatry.

\section{Review of the Mental Health Act 2001}

In July 2011, the Irish government announced a review of the Mental Health Act 2001, commencing with the formation of a Steering Group to identify key areas of the 2001 Act to be examined in more detail during the second and more detailed phase of the review. The Interim Report of the Steering Group on the Review of the Mental Health Act 2001 was published in June 2012 (Steering Group on the Review of the Mental Health Act 2001, 2012), and informed the work of the subsequent Expert Group on the Review of the Mental Health Act 2001, which met 13 times between September 2012 and September 2014, and published its report on 5 March 2015.

The Report of the Expert Group on the Review of the Mental Health Act 2001 (Expert Group on the Review of the Mental Health Act 2001, 2015) presents 165 recommendations relating to virtually all areas of the Act. Overall, it recommends that insofar as practicable, a rights based approach should be adopted throughout any revised mental health legislation' (p. 15) and that the principle of 'best interests' [Mental Health Act 2001,

* Address for correspondence: B. D. Kelly, Department of Adult Psychiatry, UCD School of Medicine and Medical Science, Mater Misericordiae University Hospital, University College Dublin, 62/63 Eccles Street, Dublin 7, Ireland.

(Email: brendankelly35@gmail.com)
Section 4(1)] should be replaced by 'the following list of guiding principles of equal importance' to 'be specified in the new law':

- The enjoyment of the highest attainable standard of mental health, with the person's own understanding of his or her mental health being given due respect.

- Autonomy and self-determination.

- Dignity (there should be a presumption that the patient is the person best placed to determine what promotes/compromises his or her own dignity).

- Bodily integrity.

- Least restrictive care.

The Report recommends that references to 'mental disorder' in the 2001 Act (Section 3) be removed and the Act should no longer provide definitions for 'severe dementia' or 'significant intellectual disability'. Instead, 'mental illness' should be re-defined as 'a complex and changeable condition where the state of mind of a person affects the person's thinking, perceiving, emotion or judgement and seriously impairs the mental function of the person to the extent that he or she requires treatment' (p.17). This is similar, although not identical, to the re-definition of 'mental disorder' in the Mental Health Act 2007 in England and Wales, which removed the four categories outlined in the 1983 Act and re-defined 'mental disorder' as 'any disorder or disability of the mind' [Section 1(2)]. 


\section{Criteria for involuntary admission}

The Expert Group Report recommends new criteria for involuntary admission as follows:

a. The individual is suffering from mental illness of a nature or degree of severity, which makes it necessary for him or her to receive treatment in an approved centre that cannot be given in the community.

b. It is immediately necessary for the protection of life of the person, for protection from a serious and imminent threat to the health of the person or for the protection of other persons that he or she should receive such treatment, and it cannot be provided unless he or she is detained in an approved centre under the Act.

c. The reception, detention and treatment of the person concerned in an approved centre would be likely to benefit the condition of that person to a material extent (p. 22).

The Report recommends defining treatment 'to include treatment to all patients admitted to or detained in an approved centre' (i.e. not just involuntary patients) and to include 'ancillary tests required for the purposes of safeguarding life, ameliorating the condition, restoring health or relieving suffering'; in addition, 'the provision of safety and/or a safe environment alone does not constitute treatment' (p. 18).

With regard to exclusions from detention, the 2001 Act stated that a person could not be involuntarily admitted 'by reason only of the fact that the person (a) is suffering from a personality disorder, (b) is socially deviant, or (c) is addicted to drugs or intoxicants' [Section 8(2)]. The Expert Group Report recommends adding '(d) has an intellectual disability' (p. 23) to this list, consistent with the elimination of 'significant intellectual disability' as a category of 'mental disorder' and in furtherance of the principles of the Convention on the Rights of Persons with Disabilities [CRPD; United Nations (UN), 2006]. A person with intellectual disability could be detained only if he or she fulfilled the revised definition of 'mental illness' and the other proposed detention criteria.

\section{Voluntary and 'intermediate' patients}

Given the various court decisions regarding the definition of 'voluntary patient' in the 2001 Act, ${ }^{1}$ which did not require capacity (Section 2), the Expert Group Report places considerable emphasis on assessing capacity, when indicated, before voluntary admission:

\footnotetext{
${ }^{1}$ EHv Clinical Director of St. Vincent's Hospital and Ors [2009] IEHC 69; EH v St. Vincent's Hospital and Ors [2009] IESC 46.
}

If following the capacity assessment, it is deemed that a person has capacity to admit themselves, a voluntary admission may proceed. If it is deemed that they need support to understand, to make or to convey their decision, that support must be provided to assist the voluntary admission process. If it is deemed that they do not have capacity in relation to this decision, and the person has a mental illness, they may only be admitted on an involuntary basis, provided they satisfy all the criteria for detention. A person who lacks capacity and has a mental illness, but does not fulfil the criteria for detention, may in specified circumstances be admitted as an 'intermediate' patient (pp. 27-28).

On this basis, 'a voluntary patient should be defined as a person who has the capacity (with support if required) to make a decision regarding admission to an approved centre and who, where the person retains capacity, formally gives his/her informed consent to such admission, and subsequent continuation of voluntary inpatient status and treatment on an ongoing basis as required' (p. 30).

It is proposed that a 'new category of patient', termed an 'intermediate patient', should be introduced, comprising patients who do 'not have the capacity to consent to [voluntary] admission and equally do not fulfil the criteria for involuntary detention' (p. 33). These patients will not be detained but will have the review mechanisms and protections of a detained person. For such patients, the mental health tribunal would focus on the question of capacity.

\section{Involuntary admission process}

Regarding the involuntary admission process, the Expert Group Report proposes that 'there should be a more expanded and active role for authorised officers' (p. 36); that is, officers of the public health service who 'after consultation with family/carers where possible and appropriate, make the decision on whether or not an application for involuntary admission of the person should be made' (p. 37). The Report recommends that 'an authorised officer should be the person to sign all applications for involuntary admission to an approved centre (this also includes change of patient status in an approved centre from voluntary to involuntary $[\ldots])$. This will have the effect of reducing the burden on families/carers in these difficult circumstances and reducing the involvement of Gardaí in the admission process' (p. 37). 'An application by an authorised officer to involuntarily admit a person to an approved centre shall remain in force for seven days from the time of the first application' (p. 37) and will need to be supported 
by a 'recommendation', completed by a registered medical practitioner within 24 hours (p. 38).

If a person is taken into custody by the Gardaí with a view to involuntary admission, the initial assessment 'should take place as soon as possible after the person is taken into custody' and in any case within 24 hours; and there should be a second 24-hour period in which the registered medical practitioner must carry out his or her assessment (p. 37). These measures are designed to minimise the time that mentally ill persons spend in police custody.

Following completion of the application (by the authorised officer) and recommendation (by a registered medical practitioner), and within 24 hours of the person's arrival at the inpatient facility, the involuntary 'admission must be certified by a consultant psychiatrist after examination of the patient and following consultation with at least one other mental health professional of a different discipline that is and/or will be involved in the treatment of the person in the approved centre. The opinion of that other mental health professional should be officially recorded' (p. 39). This requirement broadens multi-disciplinary input in to the decision-making process, but still leaves the final decision with the consultant psychiatrist.

If medical or surgical treatment is urgently required before arrival at the psychiatric inpatient facility (e.g. following overdose or injury), 'the patient may first be treated in an emergency department, hospital or clinic', but the '24-hour timeframe for the admission process to the approved centre should commence on arrival at the emergency department, hospital or clinic as though it was the approved centre named in the application and the appropriate assessment and the making of an order should be done within that timeframe' (p. 41). This provision ensures that medical and surgical care is provided as appropriate, but not at the expense of psychiatric care.

If psychiatric treatment is urgently required before the consultant psychiatrist seeing the patient and completing the detention order, it can be provided if 'the consultant psychiatrist, after consultation (to be officially recorded) with another health care professional is of the opinion that it is necessary in emergency circumstances' (p. 41). 'Emergency in this situation means that the treatment is deemed immediately necessary, that the person's actual behaviour is injurious to self or others and no other safe option is available'.

\section{Other proposed revisions}

The Expert Group Report also makes various recommendations regarding mental health tribunals, including re-naming them 'mental health review boards' (p. 47) (Box 1).
The recommendations regarding oversight are especially welcome, particularly the recommendation 'to allow information in relation to decisions of review boards to be published in anonymised form which will ensure patient confidentiality' and 'provide for the oversight of the integrity of the process of review boards by the Mental Health Commission' (p. 49).

Various other recommended changes in the Report relate to:

- mandatory multi-disciplinary consultation for renewal orders (p. 50);

- reducing the maximum duration of a renewal order from 12 to 6 months (p. 50);

- reducing periods of 'absence with leave' to a maximum of 14 days (p. 51);

- removing the onus of proof from the patient in Circuit Court appeals (p. 53);

- altering the procedure for detaining voluntary inpatients who fulfil detention criteria, so that it is essentially the same as that for detaining individuals from the community (with slight modifications to permit holding power for up to 24 hours initially, and it will no longer be necessary for the voluntary inpatient to request to leave to invoke this process) (pp. 55-56);

- requiring informed consent for the treatment of voluntary patients (p. 59) and mandatory multidisciplinary involvement in treatment decisions for involuntary patients who lack capacity (p. 60);

- limiting administration of involuntary treatment (including medication and ECT) to detained patients who lack capacity (i.e. no longer permitting involuntary treatment of capable 'unwilling' persons) (pp. 61-63);

- requiring a second opinion within 21 days (as opposed to the current 3 months) for administration of medication to detained patients who lack capacity, and requiring that such medication must be 'of therapeutic material benefit to the patient' (p. 63);

- various measures relating to 'provision of information' (pp. 64-65) and 'care-plans', which will be examined by mental health review boards (pp. 65-67; Box 1).

Other measures in the Expert Group Report relate to inspections of mental health services (to include community facilities) (pp. 74-76), children (pp. 67-74; which are beyond the scope of the present paper) and advance healthcare directives, which can be over-ruled under certain circumstances in the case of detained patients; however, such over-rulings must be notified to the Inspector of Mental Health Services within 3 days (pp. 76-79).

\section{'Best interests', benefit and the direction of change}

The package of measures outlined in the Report of the Expert Group on the Review of the Mental Health Act 2001 is both complex and interesting. The proposed elimination 
Box 1 Proposed changes to mental health tribunals ('Mental Health Review Boards') in the Report of the Expert Group on the Review of the Mental Health Act 2001 (2015).

Title and power

- Mental health tribunals should in future be re-named 'mental health review boards'.

- Although decisions about the nature and content of treatment remain within the remit of the multidisciplinary mental health team, review boards should have the authority to establish whether there is an individual care-plan in place and if it is compliant with the law.

- Review boards should also establish that the views of the patient as well as those of the multi-disciplinary team were sought in the development of the care-plan.

\section{Timing}

- The patient's detention must be reviewed by a review board no later than 14 days after the making of the admission order or the renewal order concerned (as opposed to the current 21 days).

\section{Composition}

- There should be no change in the current make up of review boards at this stage. The question of having a one-person review board should be re-examined in any future review of the mental health legislation.

- The review board members must continue to be clearly separate from the original decision-maker and those conducting the independent multi-disciplinary assessment for the review board.

- The 'other person' appointed to the review board should be known as the 'community member', and the person appointed to this role should not be or never have been a medical practitioner, nurse or mental health professional, barrister or solicitor in the state or in another jurisdiction.

\section{Attendance}

- A patient should have a legal right to have a review board deferred for specified periods (two periods of 14 days) if that is his/her wish. The deferral would have to be sought through the patient's legal representative.

- The following individuals must attend a review board: legal representative of the patient and responsible treating clinician.

- The following individuals may attend a review board: patient, who must always have a right to attend the review board; advocate, at the invitation of the patient exercising his/her right to such support; independent psychiatrist who undertook pre-review board assessment, if the review board so requests; and the author of the psychosocial report or, if they are unable to attend, another member of the multi-disciplinary team may attend on their behalf if the review board so requests.

- It should be a matter for the review board to decide which additional persons should attend the review board hearing other than the absolute right of the patient to attend, their legal representative and their advocate, if the patient so requests.

\section{Role of the independent psychiatrist}

- The patient's detention must be subject to an assessment report by an independent psychiatrist with input (to be officially recorded) from another mental health professional of a different discipline to be carried out within 5-7 days of the review board hearing.

- The range of mental health professionals that the independent psychiatrist must consult with for a Section 17 assessment should be specified.

- A psychosocial report should also be carried out by a member of the multi-disciplinary team from the approved centre who is registered with the appropriate professional regulatory body (i.e. CORU, Nursing and Midwifery Board or Medical Council) in the same time-frame as that recommended for the independent psychiatrist report. This report should concentrate on the non-medical aspects of the patient's circumstances. 


\section{Oversight}

- The revised legislation should provide for the oversight of the integrity of the process of review boards by the Mental Health Commission in line with best practice.

- This would include a mechanism to allow information in relation to decisions of review boards to be published in anonymised form, which will ensure patient confidentiality. This will allow such decisions to be available for the Mental Health Commission and/or the public to view.

Adapted from Expert Group on the Review of the Mental Health Act 2001, 2015.

of the principle of 'best interests', in particular, contrasts sharply with recent developments in neighbouring jurisdictions. In Northern Ireland, for example, the Mental Capacity Bill 2014 (which fuses mental health legislation and capacity legislation into a single bill) includes, as a principle, that every 'act or decision must be done, or made, in the best interests of the person' [Section 1(7)].

Section 6 of the Northern Irish bill provides detailed guidelines to prevent over-paternal interpretation of 'best interests', including a legal requirement to 'take into account' (a) the patient's ( $\left.\mathrm{P}^{\prime} \mathrm{s}\right)$ 'past and present wishes and feelings (and, in particular, any relevant written statement made by $\mathrm{P}$ when P had capacity); (b) the beliefs and values that would be likely to influence $\mathrm{P}^{\prime}$ s decision if $\mathrm{P}$ had capacity; and (c) the other factors that $\mathrm{P}$ would be likely to consider if able to do so'. There is also a legal requirement to 'consult the relevant people about what would be in P's best interests' and 'take into account the views of those people' (if practicable) [Section 6(7)].

In England and Wales, the Mental Health Act 2007 includes 'patient well-being and safety' as a principle (Section 8), and the Mental Health (Care and Treatment) (Scotland) Act 2003 includes 'the importance of providing the maximum benefit to the patient' [Section 1(3)(f)] in its principles. The McManus Review (Review Group, 2009) did not propose changing this in Scotland, and nor does Scotland's Mental Health (Scotland) Bill 2014.

This is an important issue. The history of psychiatry is replete with examples of various actors (state, private, medical) taking actions, which were societally convenient but of questionable benefit to the mentally ill (Shorter, 1997; Scull, 2005). A clear requirement for benefit to the patient is a critical element in any mental health legislation that seeks genuinely to protect rights and focus public, professional and political attention on the need to provide services that are effective, efficient, beneficial and empowering for the mentally ill.

\section{'The highest attainable standard of mental health'}

Against this background, considerable importance will attach to the interpretation of the proposed new principle: 'the enjoyment of the highest attainable standard of mental health, with the person's own understanding of his or her mental health being given due respect' ( $p$. 15). This principle is clearly consistent with Ireland's 2006 mental health policy, A Vision for Change (Expert Group on Mental Health Policy, 2006; Guruswamy \& Kelly, 2006), and also with Ireland's public commitment to the WHO's Mental Health Declaration for Europe (WHO Ministerial Conference on Mental Health, 2005a) and Mental Health Action Plan for Europe (WHO Ministerial Conference on Mental Health, 2005b), both of which emphasise the importance of adequate resourcing of mental health services (Mudiwa, 2005) and the need for services to benefit patients.

The WHO has made specific and robust recommendations in relation to mental health law in individual states (WHO, 1996), placing a strong and welcome emphasis on the civil, political, economic and social rights of persons with mental disorder (WHO, 2005). At present, Ireland's legislation accords with these standards in part but not completely, with particular deficits relating to economic and social rights (Kelly, 2011).

In addition, even if the Expert Group's recommendations are implemented, the Mental Health Act 2001, and the link it draws between 'mental disorder' and involuntary detention, still accords poorly with the CRPD requirement that the existence of a disability shall in no case justify a deprivation of liberty' [Article 14(1)(b)] (UN, 2006). As a result, if certain persons with mental disorder (e.g. those sufficiently ill to be detained) fit the UN definition of 'persons with disabilities', then Ireland's Mental Health Act 2001 violates this CRPD requirement, as does mental health legislation in England, Wales, Northern Ireland and Scotland (Bennett, 2014; Kelly, 2014).

It is unlikely that this apparent inconsistency with the CRPD will be resolved definitively in any of these jurisdictions in the near future. In the meantime, the 165 recommendations presented in the Report of the Expert Group on the Review of the Mental Health Act 2001 reflect the most recent advice on legislative change provided to the Minister for Primary Care, Social Care (Disabilities \& Older People) and Mental Health. Although the Report clearly reflects the likely direction of future 
reform in this area, the precise nature of specific legislative changes, which may result from the Report, has yet to be determined.

\section{Acknowledgement}

This paper contains public sector information licensed under the Open Government Licence v1.0 and Open Government Licence v2.0; and Scottish Parliamentary information licensed under the Open Scottish Parliament Licence v1.0.

\section{Conflicts of Interest}

The present author (B.D.K.) was nominated to the Expert Group on the Review of the Mental Health Act 2001 by the College of Psychiatrists of Ireland and appointed to the group by Minister Kathleen Lynch, Minister for Primary Care, Social Care (Disabilities \& Older People) and Mental Health, in 2012. This paper is written in his personal capacity, as a psychiatrist. There is no other interest to declare.

\section{References}

Bennett DM (2014). The UN convention on the rights of persons with disabilities and UK mental health legislation. British Journal of Psychiatry 205, 76-77.

Expert Group on Mental Health Policy (2006). A Vision for Change. The Stationery Office: Dublin.

Expert Group on the Review of the Mental Health Act 2001 (2015). Report of the Expert Group on the Review of the Mental Health Act 2001. Department of Health and Children: Dublin.
Guruswamy S, Kelly BD (2006). A change of vision? Mental health policy. Irish Medical Journal 99, 164-166.

Kelly BD (2011). Mental health legislation and human rights in England, Wales and the Republic of Ireland. International Journal of Law and Psychiatry 34, 439-454.

Kelly BD (2014). An end to psychiatric detention? Implications of the United Nations convention on the rights of persons with disabilities. British Journal of Psychiatry 204, 174-175.

Mudiwa L (2005). Ireland signs WHO declaration on mental health. Medicine Weekly 3, 18.

Review Group (2009). Limited Review of the Mental Health (Care and Treatment) (Scotland) Act 2003: Report. Scottish Government: Edinburgh.

Scull A (2005). The Most Solitary of Afflictions: Madness and Society in Britain, 1700-1900. Yale University Press: New Haven and London.

Shorter E (1997). A History of Psychiatry: From the Era of the Asylum to the Age of Prozac. John Wiley and Sons: New York.

Steering Group on the Review of the Mental Health Act 2001 (2012). Interim Report of the Steering Group on the Review of the Mental Health Act 2001. Department of Health: Dublin.

United Nations (UN) (2006). Convention on the Rights of Persons with Disabilities. United Nations: New York.

World Health Organisation (1996). Mental Health Law: Ten Basic Principles. World Health Organisation: Geneva.

World Health Organisation (2005). WHO Resource Book on Mental Health, Human Rights and Legislation. World Health Organisation: Geneva.

World Health Organisation Ministerial Conference on Mental Health (2005a). Mental Health Declaration for Europe. World Health Organisation: Helsinki.

World Health Organisation Ministerial Conference on Mental Health (2005b). Mental Health Action Declaration for Europe. World Health Organisation: Helsinki. 